\title{
Decreased health-related quality of life in patients with diabetic foot problems
}

This article was published in the following Dove Press journal: Diabetes, Metabolic Syndrome and Obesity:Targets and Therapy

\section{Jin Sothornwit ${ }^{\prime}$}

Gulapar Srisawasdi

Atchara Suwannakin ${ }^{2}$

Apiradee Sriwijitkamol'

'Division of Endocrinology and Metabolism, Department of Medicine, Faculty of Medicine Siriraj Hospital, Mahidol University, Bangkok Noi, Bangkok, Thailand; ${ }^{2}$ Foot Clinic, Department of Rehabilitation Medicine, Faculty of Medicine Siriraj Hospital, Mahidol University, Bangkok Noi, Bangkok, Thailand
Correspondence: Apiradee Sriwijitkamol Division of Endocrinology and Metabolism, Department of Medicine, Faculty of Medicine Siriraj Hospital, Mahidol University, 2 Arun Amarin Road, Siriraj Subdistrict, Bangkok Noi, Bangkok 10700, Thailand

Tel +6624197000

Email apiradeesi99@hotmail.com
Purpose: The aim of this study was to investigate health-related quality of life (HRQoL) in patients with diabetic foot problems and compare the HRQoL between diabetic patients with: 1) diabetic foot problems (DF), including diabetic foot ulcer (DFU) or amputation (AMPU); 2) other diabetic complications (COM), such as diabetic retinopathy (DR), end-stage renal disease (ESRD), or coronary artery disease (CAD); and 3) no diabetic complication (CON).

Patients and methods: A total of 254 diabetic patients were studied in a cross-sectional setting. HRQoL was evaluated using Thai version of the Euro Quality of Life Questionnaire (EuroQoL), with five dimensions and five-level scale (EQ-5D-5L). Utility scores were calculated using time trade-off methods.

Results: A total of 141 patients in the DF group (98 DFU and 43 AMPU groups), 82 in the COM group (27 DR, $28 \mathrm{ESRD}$, and $27 \mathrm{CAD}$ groups), and 31 in the CON group were interviewed. The mean age was $63.2 \pm 12.1$ years, body mass index was $24.9 \pm 4.7 \mathrm{~kg} / \mathrm{m}^{2}$, mean hemoglobin A1c was $7.7 \pm 2.1 \%$, duration of diabetes was $13.1 \pm 9.9$ years, and the mean utility scores were $0.799 \pm 0.25$. After having DF, $21 \%$ of patients had lost their jobs. The COM group had lower utility scores than the CON group. Among the diabetic complications, the DF group had the lowest mean utility scores as compared to the COM and CON groups $(0.703 \pm 0.28$ in the DF group, $0.903 \pm 0.15$ in the COM group, and $0.961 \pm 0.06$ in the CON group, $P<0.01)$. There was no difference in the mean utility scores between DFU and AMPU groups. Patients in the DF group reported moderate-to-severe problem in all dimensions more than the other groups.

Conclusion: DF have the greatest negative impact on HRQoL. Therefore, diabetic foot care should be emphasized in clinical practice to prevent foot complications.

Keywords: health-related quality of life, diabetic complications, diabetic foot problems

\section{Introduction}

Diabetes mellitus is the second most common cause of non-communicable diseases in Thailand. ${ }^{1}$ Complications from diabetes result in both lower quality of life and higher cost of treatment. Data from Thai Ministry of Public Health in 2014 showed that diabetes was the first leading cause of burden of disease in females. ${ }^{2}$ One of the most common diabetic-related complications is the diabetic foot problem. This complication, caused by peripheral arterial disease or peripheral neuropathy, brings about poor ulcer healing, infection, or even leg amputation. Health-related quality of life (HRQoL) is adversely affected by diabetic foot problems in all dimensions, especially mobility. Until now, there is a paucity of data on the effects of foot ulcers on HRQoL in diabetic patients. In previous studies, HRQoL of patients with diabetic foot problems was higher 
in the patients treated with minor foot amputation than the patients with ongoing foot ulcers. ${ }^{3-5}$ However, according to many doctors and patients, amputation seems to be worse and should be the last therapeutic option. ${ }^{6}$ Moreover, the cost of amputation is higher than the cost of ulcer dressing. In Siriraj Hospital, Thailand, the average cost per inpatient stay for lower limb amputations was 80,000 THB during 2002-2004.7 The cost of ulcer dressing varied based on the type of ulcer and the dressing techniques. On average, the cost of diabetic foot ulcer treatment was increased by $88 \%$ as compared to diabetic patients without any complications. ${ }^{8}$ To the best of our knowledge, no studies have been conducted on the quality of life in patients with diabetic foot compared to other diabetic complications in Thailand. The result of this study may be useful for future cost-effectiveness analysis research.

We used the Euro Quality of Life Questionnaire (EuroQoL), ${ }^{9}$ which was a standardized measure of health status developed by the Euro Quality of Life Group in order to provide a simple and generic measure of health for clinical and economic appraisal. Five-level EuroQol five-dimension questionnaire (EQ-5D-5L), the latest version, was used in this study. This questionnaire was recommended for the cost utility analysis of new interventions and treatments by many international institutes, for example, the National Institution for Clinical Excellence of the United Kingdom, the US panel on costeffectiveness in Health and Medicine of the United States, and Canadian Coordinating Office for Health Technology Assessment (CCOHTA) of Canada. ${ }^{10,11}$ Therefore, this study was conducted to investigate HRQoL, using EQ-5D-5L in patients with diabetic foot problems, and compare the HRQoL between diabetic patients with 1) diabetic foot problems, including diabetic foot ulcer or amputation; 2) other diabetic complications such as diabetic retinopathy, end-stage renal disease, or coronary artery disease; and 3 ) no diabetic complication.

\section{Patients and methods}

\section{Patients}

Diabetic patients aged $\geq 18$ years, who had been followed up at a diabetic clinic, a foot clinic, a dressing room, or a laser eye surgery clinic, Siriraj Hospital, Thailand, during January 2014 to September 2016, were randomly recruited. We excluded patients with ulcers from causes other than diabetic foot ulcer, for example, ulcer after a motor vehicle accident or malignant ulcer. We classified the patients into three major groups as follows:

1. Diabetic patients who have diabetic foot problems (DF group) were divided into the following two subgroups:
- Diabetic patients who have received amputation (AMPU group) were divided into the following subgroups according to the level of amputation:

Below ankle amputation

Above ankle amputation

- Diabetic foot ulcer (DFU group) was divided according to the University of Texas diabetic wound classification into the following four subgroups:

Clean wound (non-ischemic, non-infected ulcer)

Non-ischemic, infected ulcer

Ischemic, non-infected ulcer

Ischemic, infected ulcer

2. Diabetic patients with other diabetic complications (COM group) were divided into the following three subgroups:

- Diabetic retinopathy (DR group): including severe nonproliferative DR and proliferative DR groups

- End-stage renal disease (ESRD group): patients requiring renal replacement therapy (RRT) or kidney transplantation (KT)

- Coronary artery disease (CAD group): patients with a history of acute coronary syndrome or who underwent percutaneous coronary artery intervention and coronary artery bypass graft

3. Diabetic patients without diabetic complications (CON group) were recruited to serve as a control group.

This study was approved by the Siriraj Institutional Review Board. All participants provided written informed consent for study participation before enrolling in the study.

\section{Study protocol}

After patients signed the consent, they answered the Thai version of EQ-5D-5L questionnaire by themselves, which took around 15 minutes to complete. For those who have reading problem, the investigator, face to face, read the question for them. Each patient was allowed to take time to answer the questionnaire. To provide further background information about the patients, some additional questions about living conditions were included in the questionnaire.

\section{Questionnaire}

EQ-5D-5L was used in this study and was verified by the Health Intervention and Technology Assessment Program (HiTAP) that Thai version of EQ-5D-5L can be used to evaluate health status in Thai population. ${ }^{12}$ EQ-5D-5L assesses health status across five dimensions including mobility, selfcare, usual activities, pain/discomfort, and anxiety/depression. Each dimension has five response levels including no prob- 
lems, slight problems, moderate problems, severe problems, and extreme problems. After each patient answered the questionnaire, the EQ-5D-5L health status was converted to utility value. The utility value was the respondents' own assessment of their health status. It was derived by using country-specific time-trade-off (TTO) model as shown in Figure 1.

The program to calculate the utility value can be downloaded from the HiTAP website: http://www.hitap.net/ documents/89762. ${ }^{12}$ The utility value ranges from -1 to 1 . The value of 1 meant that the respondents assess their health status as good health. The value of $<1$ meant that their health status was very poor.

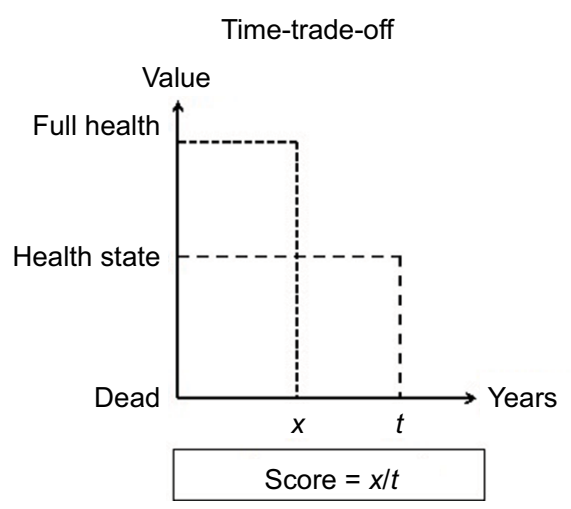

Figure I The time-trade-off model calculates the utility score.

Notes: If respondents were living with the health state, each one of them has $t$ years to live. To live in full health, they need to give up some life years to live for a shorter period. $X$ is the number of years of life expected to be lived in full health.

\section{Statistical analyses}

Statistical analyses were performed using SPSS version 18.0 for Windows. The primary outcome was the comparison of mean utility scores between the DF, COM, and CON groups. The secondary outcome was the comparison of mean utility scores between DF, DR, ESRD, CAD, and CON groups. Data were presented as mean $\pm \mathrm{SD}$, median (range), or percentage as appropriate. Comparison between groups was tested by one-way analysis of variance (ANOVA). For all analyses, a $P<0.05$ was considered to be statistically significant.

\section{Results}

Two hundred and fifty-four diabetic patients were randomly recruited in this cross-sectional study. Of them, 141 patients (55.5\%) had diabetic foot problems (DF group), 82 patients (32.3\%) had other diabetic complications (COM group), and 31 patients (12.2\%) had no diabetic complications (CON group) as shown in Figure 2.

Demographic and clinical characteristics are shown in Table 1. The mean age of patients was $63.2 \pm 12.1$ years (range 24-92 years), the body mass index (BMI) was $24.9 \pm 4.7 \mathrm{~kg} /$ $\mathrm{m}^{2}$, the mean hemoglobin $\mathrm{A} 1 \mathrm{c}(\mathrm{HbA} 1 \mathrm{C})$ was $7.7 \pm 2.1 \%$, and the duration of diabetes was $13.1 \pm 9.9$ years. There was no difference in age, BMI, HbA1C, the duration of diabetes, and diabetes treatment regimens between each group. There were more male patients in the DF and COM groups than in the

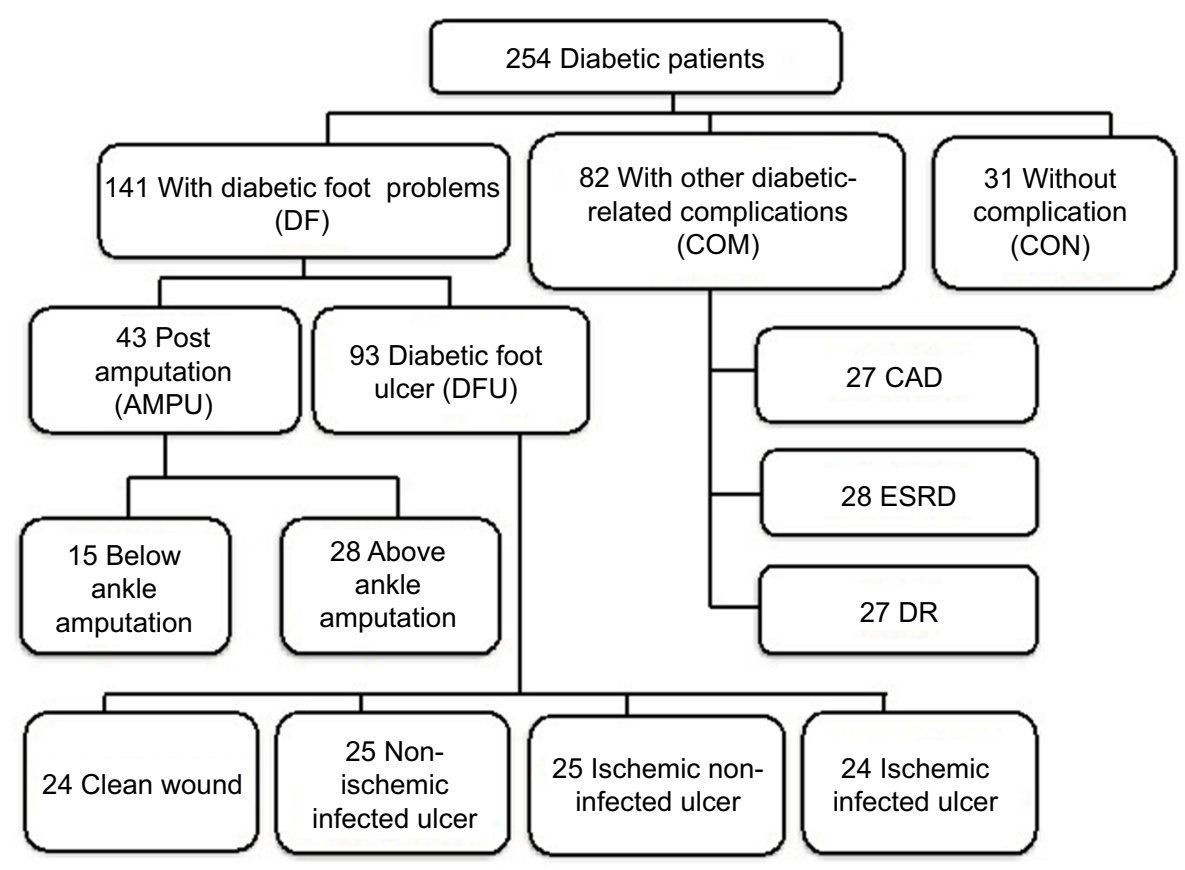

Figure 2 The number of patients in each group.

Abbreviations: $C A D$, coronary artery disease; DR, diabetic retinopathy; ESRD, end-stage renal disease. 
Table I Baseline characteristics of patients

\begin{tabular}{|c|c|c|c|c|c|}
\hline & Total $(\mathrm{N}=254)$ & $D F(N=|4|)$ & $\operatorname{COM}(\mathrm{N}=82)$ & $\operatorname{CON}(N=3 I)$ & $P$-value \\
\hline Age, years & $63(24-92)$ & $64(43-92)$ & $62(24-92)$ & $60(25-83)$ & 0.08 \\
\hline Male, $\%$ & 47 & 54 & 43 & 26 & 0.03 \\
\hline $\mathrm{BMI}, \mathrm{kg} / \mathrm{m}^{2}$ & $24.9(15.8-45.1)$ & $24.7(15.8-45)$ & $25.0(17.4-36.6)$ & $25.8(17.3-36.6)$ & 0.67 \\
\hline Duration of DM, years & I3.I (0-50) & $13.4(I-74)$ & $14.7(0-50)$ & $9.7(I-27)$ & 0.18 \\
\hline Nonsmoker, \% & 74 & 75 & 79 & 87 & 0.08 \\
\hline $\mathrm{HbAlc}, \%$ & $7.7(4.6-14.6)$ & $7.9(5-17.6)$ & $7.7(4.6-14.7)$ & $7.5(5.8-13.7)$ & 0.14 \\
\hline LDL-C, mg/dL & $89(42-25 I)$ & $89(44-186)$ & $88(42-25 I)$ & $90(53-182)$ & 0.98 \\
\hline \multicolumn{6}{|l|}{ Weight bearing status, \% } \\
\hline Full-weight & 55 & 30 & 82 & 94 & $<0.001$ \\
\hline Partial-weight & 32 & 50 & 17 & 6 & \\
\hline Non-weight & 13 & 20 & 1 & 0 & \\
\hline \multicolumn{6}{|c|}{ Occupation after diagnosed diabetic complications, \% } \\
\hline Not having a career & 61 & 62 & 66 & 60 & $<0.001$ \\
\hline Unemployed & $\mathrm{II}$ & 21 & 0 & 0 & \\
\hline Changed job & 0.4 & I & 0 & 0 & \\
\hline Working as before & 21 & 21 & 34 & 40 & \\
\hline
\end{tabular}

Note: Data presented as mean (range) or percentage.

Abbreviations: BMI, body mass index; COM, other diabetic complications; CON, control; DM, diabetes mellitus; HbA Ic, hemoglobin AI c; LDL-C, low-density lipoprotein cholesterol; DF, diabetic foot.

CON group. All of the patients in the DF group had type 2 diabetes, whereas those in COM and CON groups had $3 \%$ of type 1 diabetes and $6 \%$ of other types of diabetes, respectively. In the DF group, only $30 \%$ could walk independently, $\sim 50 \%$ had to use walking gait, and $20 \%$ could not walk. After having diabetic foot problems, $21 \%$ of patients were unemployed ( 6 of 43 patients in the AMPU group and 23 of 98 patients in the DFU group). One patient in the DFU group had to change his career. All other participants in COM or CON groups still worked as before having diabetic-related complications or diabetes.

The primary outcome of this study was the comparison of the utility values between the DF, COM, and CON groups. The mean utility scores of all the patients were $0.799 \pm 0.25$ (range $0.7-1.000,95 \%$ CI $0.768-0.830$ ). The higher utility score reflects the better quality of life. The DF group had the least mean utility score, followed by COM and CON groups, as shown in Figure 3. Those without any diabetic complication had the highest utility score, which implies that they had a good quality of life. The mean utility score of each subgroup is shown in Table $\mathrm{S} 1$.

The secondary outcome of this study was to compare the utility scores between the DF, DR, ESRD, CAD, and CON groups. Patients with diabetic foot problem had the least mean utility score as compared to other complications. The mean utility scores of the DR, ESRD, CAD, and CON groups were not statistically different as shown in Figure 4. Patients with diabetic foot problems reported moderate-to-extreme problem in each dimension more than patients with other complications and those without complication as shown in

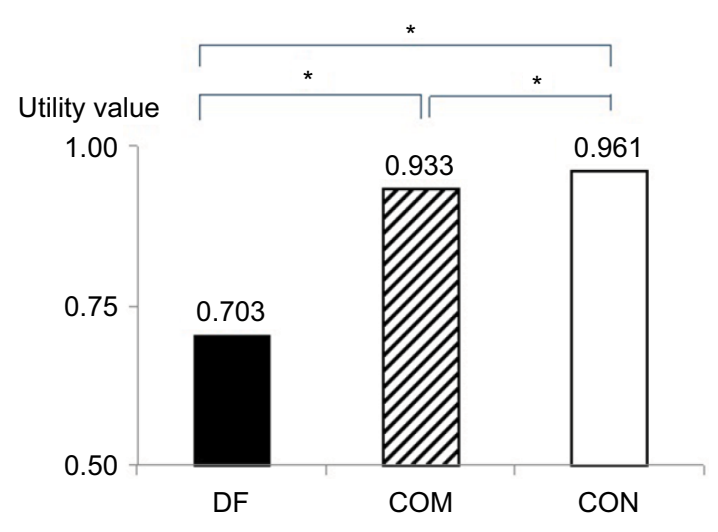

Figure 3 The utility value in the DF, COM, and CON groups.

Notes: The DF group had the least mean utility score, followed by COM and CON groups. *Statistically significant.

Abbreviations: COM, other diabetic complications; CON, control; DF, diabetic foot.

Figure 5. The only dimension having negative impact on patients with diabetic foot problems less than patients with ESRD was anxiety and depression. Comparing the utility score among patients with diabetic foot problems, there was no difference in the utility score between diabetic foot ulcer and post amputation (Figure 6A). Quality of life was not significantly different in patients who had amputation, either below or above knee amputation (Figure 6B). Among patients with diabetic foot ulcer, those with ischemic ulcer, either infected or non-infected, had the lowest utility value as compared to those without ischemic ulcer (Figure 6C). Considering the effect of weight bearing status on the quality of life, patients with non-weight-bearing had the worst quality of life than other groups (Figure 7). Diabetic foot was 
further defined according to the duration of the problems: acute, $<6$ months, and chronic, $\geq 6$ months. No patients with chronic major amputation were included in our study due to loss to follow-up. Patients with chronic ulcer had the highest utility value followed by patients with acute major amputation and then patients with acute ulcer, but there was no statistical significance (Figure 8).

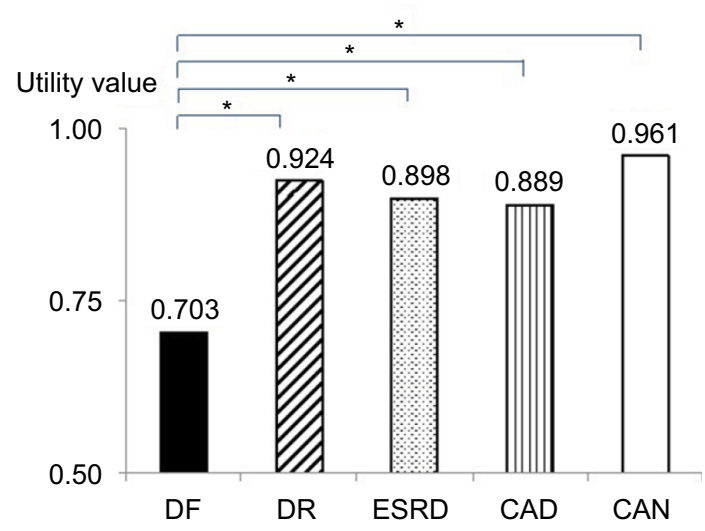

Figure 4 The utility value in DF, DR, ESRD, CAD, and CON groups.

Notes: Patients with diabetic foot problem had the least mean utility score as compared to other complications. The mean utility score among patients with DR, ESRD, CAD, and CON groups were not statistically different. *Statistically significant. Abbreviations: $C A D$, coronary artery disease; $C O N$, control; $D F$, diabetic foot: $\mathrm{DR}$, diabetic retinopathy; ESRD, end-stage renal disease.

\section{Discussion}

Diabetic foot problems had the greatest negative impact on HRQoL. In this study, it has been shown that all dimensions of HRQoL were greatly impaired in patients with diabetic foot problems as compared to those with other diabetic-related complications. HRQoL in patients treated by amputation and those with current diabetic foot ulcers was not different even though the mean utility score in patients with diabetic foot ulcer was lower than that in patients who underwent amputation, but this difference did not reach statistical significance. Among patients with diabetic foot problem, those who had weight-bearing problems and those with ischemic diabetic foot ulcer showed a significant impact on the quality of life. Pain from ischemia, dependent status after inability to walk, difficulties from daily ulcer dressing at the hospital, and unemployment stress may be the major causes of lower quality of life among patients with diabetic foot problem. Quality of life in patients with chronic diabetic foot problems was slightly better than that in patients with acute problems. Despite having diabetic foot ulcer for a long time, the patients still had poor quality of life. The factors impeding patient adaptation to diabetic foot ulcer should be searched for. Previous studies ${ }^{5,13,14}$ have shown that the mean utility score in patients with diabetic foot problem was $\sim 0.7$, which is similar to this study. HRQoL in patients with diabetic foot ulcer in

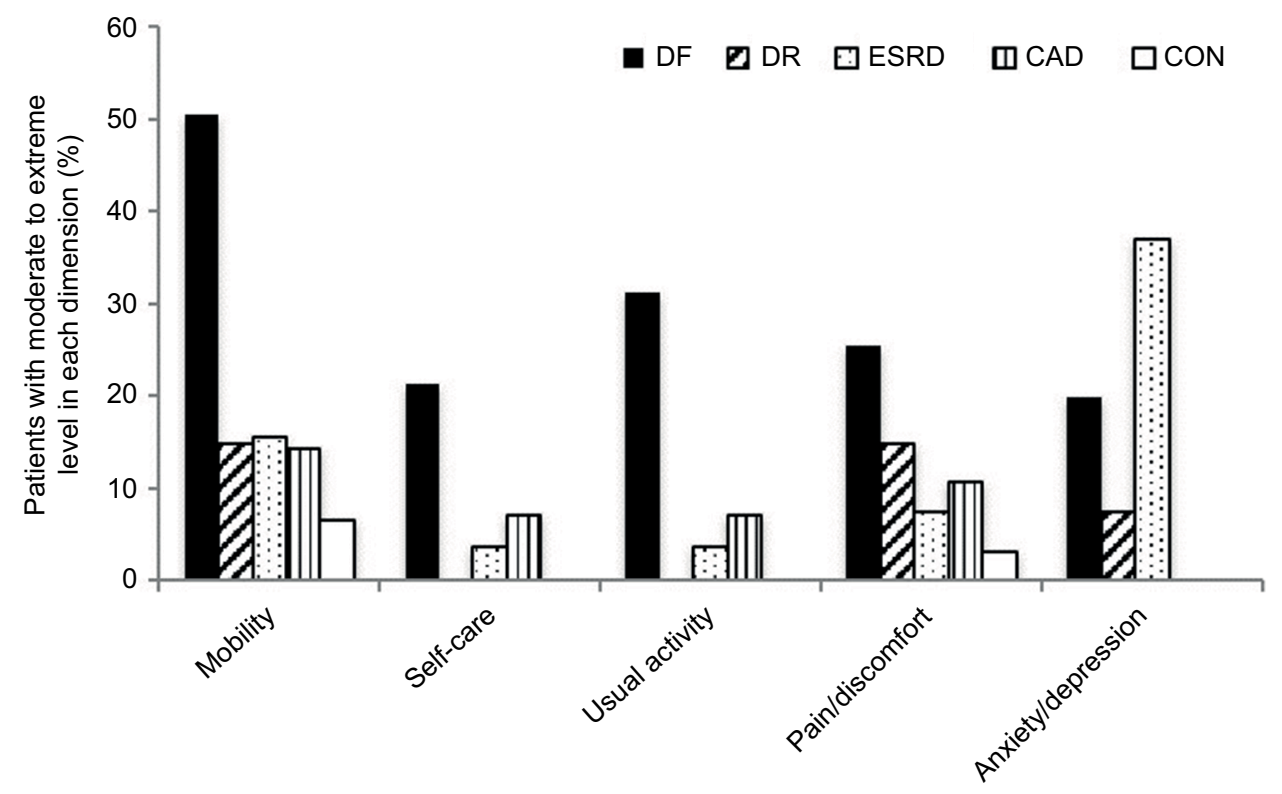

Figure 5 Percentage of patients in DF, DR, ESRD, CAD, and CON groups with moderate-to-extreme problem in each dimension.

Note: Patients with diabetic foot problems reported moderate-to-extreme problem in each dimension more than patients with other complications and those without complication.

Abbreviations: DF, diabetic foot; DR, diabetic retinopathy; ESRD, end-stage renal disease; CAD, coronary artery disease; CON, control. 
A

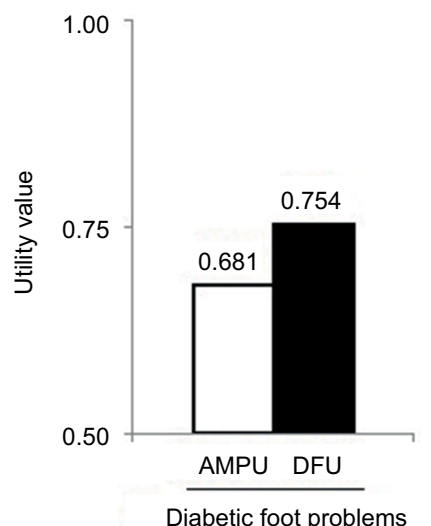

B

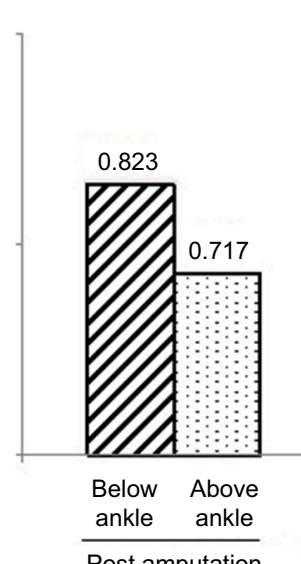

C

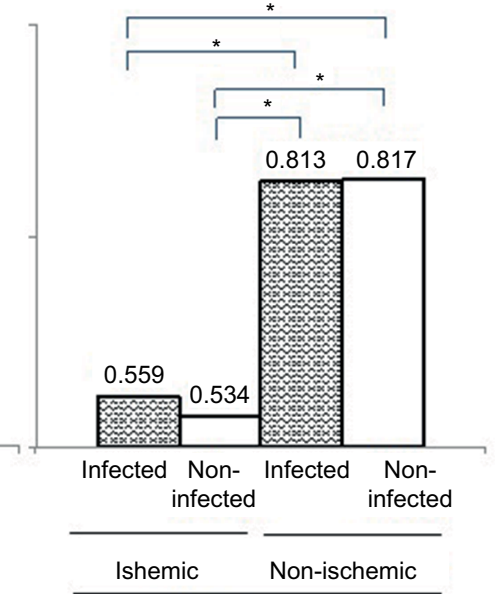

Post amputation

Diabetic foot ulcer

Figure 6 Comparison of the mean utility values among patients with diabetic foot problems.

Notes: (A) Between post amputation and diabetic foot ulcer; (B) between below and above knee amputation, and (C) between those diabetic foot ulcers. There was no difference in the utility score between diabetic foot ulcer and post amputation. Quality of life was not significantly different in patients who had amputation, either below or above knee. Among patients with diabetic foot ulcer, those with ischemic ulcer, either infected or non-infected, had the lowest utility value as compared to those without ischemic ulcer. *Statistically significant.

Abbreviations: AMPU, amputation; DFU, diabetic foot ulcer.

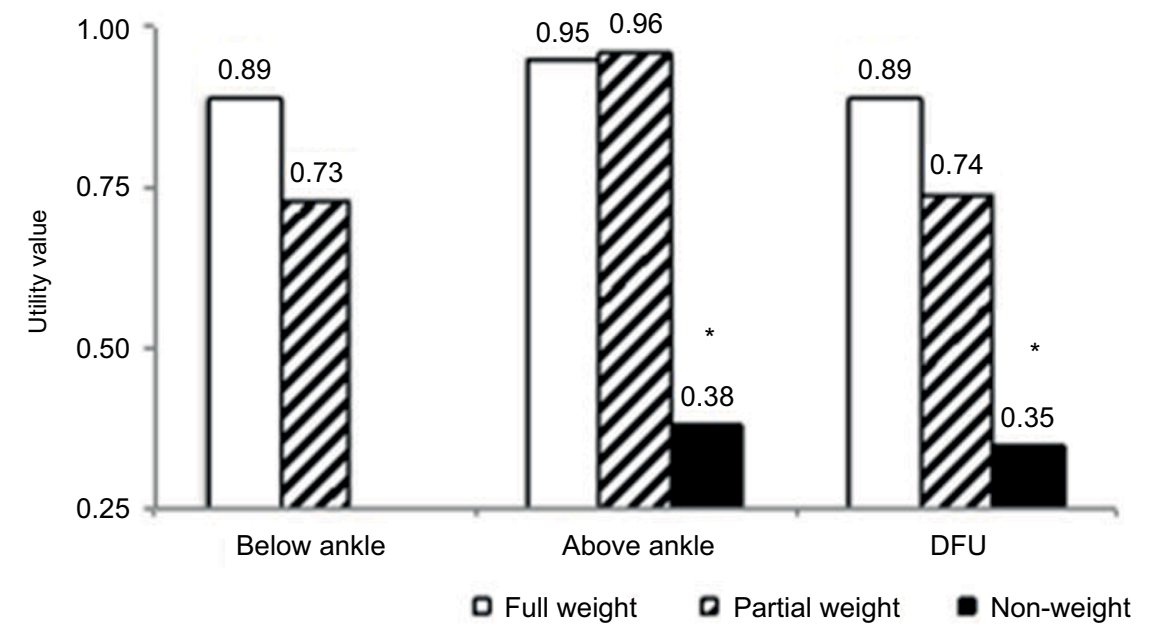

Figure 7 Comparison of the mean utility values among patients with diabetic foot problems with different weight-bearing statuses.

Notes: Patients with non-weight bearing had the worst quality of life than other groups. *Statistically significant.

Abbreviation: DFU, diabetic foot ulcer.

this study was equal to patients with foot amputation, and this result is consistent with the result from the Eurodiale study, ${ }^{15}$ which has shown that minor amputation was not associated with a negative impact on HRQoL in patients with diabetic foot ulcers. However, HRQoL in patients with diabetic foot ulcer in this study was slightly lower than the results from previous studies. ${ }^{5,13,14}$ The reason for this difference still has no explanation; we hypothesized that pain or discomfort during wound dressing or the difficulties in coming to hospital every day for wound dressing might be the reason.
Despite high prevalence of diabetic foot problems, which was $\sim 40 \%$ in our previous study, ${ }^{16}$ only $16 \%$ of patients received annual foot examination. Moreover, patients with diabetic foot problems also had either neglected or inappropriately cared for their ulcers, ${ }^{17}$ which lead to worse outcomes. The cost for diabetic foot treatment was higher than the cost for other complications. ${ }^{18}$ Diabetic foot problems can be prevented by simple measures such as examining the foot at least once a year, recognizing the foot with a high level of risk, educating the patient and 


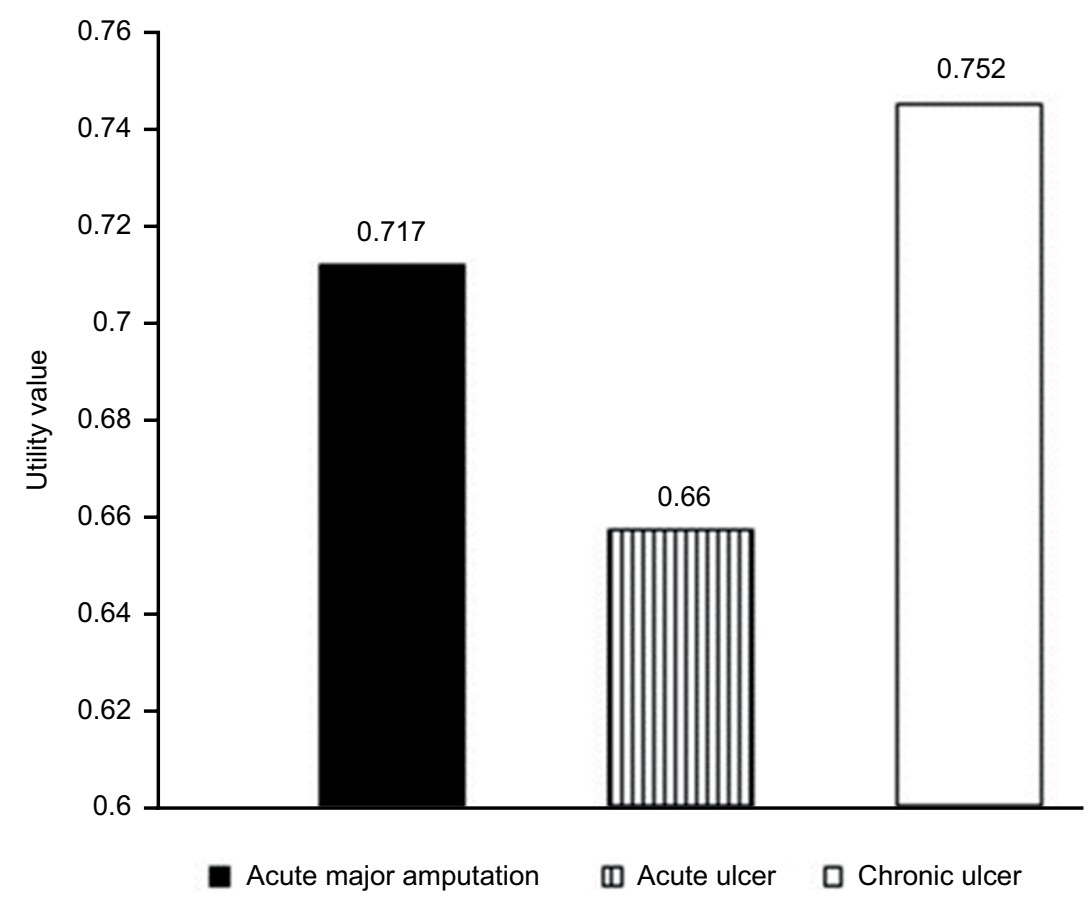

Figure 8 Comparison of the mean utility values among patients with acute major amputation, acute ulcer, and chronic ulcer. Note: There was no difference in the utility value between acute major amputation, acute ulcer, and chronic ulcer.

family about preventive foot care and adapted shoes, and emphasizing the appropriate diabetic foot care in clinical practice to prevent diabetic foot problems, which will result in the reduction of the cost of treatment and improve the quality of life in those patients.

The limitation of our study was relatively small sample sizes in DR, ESRD, and CAD groups, and therefore, there was no difference in the HRQoL between those with other diabetic complications as compared to those without diabetic complications. The other limitation of this study was the use of only a single generic instrument which was designed to be applicable across a wide range of populations, but not specific to diabetic population, which might lead to bias.

\section{Conclusion}

Diabetic foot problems had the most negative impact on quality of life. Foot care and foot assessment should be promoted for preventing diabetic foot problems.

\section{Acknowledgments}

This research did not receive any specific grant from funding agencies in the public, commercial, or not-for-profit sectors. This research was presented at the American Diabetes Association 77th Scientific Sessions; June 9-13, 2017; San Diego.

\section{Disclosure}

The authors report no conflicts of interest in this work.

\section{References}

1. Bureau of Epidemiology, Department of Disease Control, Ministry of Public Health, Thailand. Chronic Diseases Surveillance Report 2012. Available from: http://www.boe.moph.go.th/files/ report/20140109_40197220.pdf. Accessed November 15, 2017.

2. Bureau of Policy and Strategy, Ministry of Public Health, Thailand. Statistical Thailand 2014. Available from: http://bps.moph.go.th/new_bps/ sites/default/files/health_statistics2557.pdf. Accessed November 15, 2017.

3. Brod M. Quality of life issues in patients with diabetes and lower extremity ulcer: patients and caregivers. Qual Life Res. 1998;91:733-737.

4. Price P. The diabetic foot: quality of life. Clin Infect Dis. 2004;39(Suppl 2): S129-S131.

5. Redekop WK, Stolk EA, Kok E, et al. Diabetic foot ulcers and amputations: estimates of health utility for use in cost effectiveness analyses of new treatments. Diabetes Metab. 2004;30:549-556.

6. Carrington AL, Mawdsley SK, Morley M, Kincey J, Boulton AJ. Psychological status of diabetic people with or without lower limb disability. Diabetes Res Clin Pract. 1996;32(1-2):19-25.

7. Thirapatarapong W, Srisawasdi G. Epidemiology and direct cost of diabetes-related lower extremity amputations at Siriraj Hospital. J Rehabil Med. 2008;18(2):65-69.

8. Riewpaiboon A, Pornlertwadee P, Pongsawa K. Diabetes cost model of a hospital in Thailand. Value Health. 2007;10(4):223-230.

9. Williams A. The EuroQol instrument. In: Kind P, Brooks R Rabin R, editors. EQ-5D Concepts and Methods: A Developmental History. Dordrecht, the Netherlands: Springer; 2005:1-17.

10. Brooks R, Rabin R, Charro FD. The Measurement \& Valuation of Health Status Using EQ-5D: A European Perspective. Dordrecht, the Netherlands: Kluwer Academic Publishers; 2003. 
11. Earnshaw J, Lewis G. NICE guide to the methods of technology appraisal: pharmaceutical industry perspective. Pharmacoeconomics. 2008;26(9):725-727.

12. Health Intervention Technology and Assessment Program. Healthrelated quality of life measure (EQ-5D-5L): the development, psychometric testing, and its preference-based score in Thai population. Available from: http://www.hitap.net/wp-content/uploads/2014/06/ proposal_eq5d51.pdf. Accessed November 15, 2017.

13. Sullivan SD, Lew DP, Devine EB, Hakim Z, Reiber GE, Veenstra DL. Health state preference assessment in diabetic peripheral neuropathy. Pharmacoeconomics. 2002;20(15):1079-1089.

14. Ragnarson G, Apelquist J. Health-related quality of life in patients with diabetes mellitus and foot ulcers. J Diabetes Complications. 2000;14(5):235-241.
15. Pickwell K, Siersma V, Kars M, et al. Minor amputation does not negatively affect health-related quality of life as compared with conservative treatment in patients with a diabetic foot ulcer: an observational study. Diabetes Metab Res Rev. 2017;33:e2867.

16. Sriwijitkamol A, Moungngern Y, Wannasaeng S. Assessment and prevalences of diabetic complications in 722 Thai type 2 diabetes patients. J Med Assoc Thai. 2011;94(1):168-174.

17. Sriussadaporn S, Ploybutr S, Nitiyanant W, Vannasaeng S, Vichayanrat A. Behavior in self-care of the foot and foot ulcers in Thai noninsulin dependent diabetes mellitus. J Med Assoc Thai. 1998;81(1): 29-35.

18. Riewpaiboon A, Chatterjee S, Piyauthakit P. Cost analysis for efficient management: diabetes treatment at a public district hospital in Thailand. Int J Pharm Pract. 2011;19(5):342-349. 


\section{Supplementary material}

Table SI The mean utility scores of 10 subgroups

\begin{tabular}{|c|c|c|c|c|c|}
\hline Patient groups & n (\%) & Mean utility score & SD & Range & $95 \% \mathrm{Cl}$ \\
\hline$\overline{D F}$ & $14 \mid(55.5)$ & 0.703 & 0.28 & $0.007-1.000$ & $0.656-0.750$ \\
\hline AMPU & $43(30.5)$ & 0.754 & & $0.030-1.000$ & $0.673-0.835$ \\
\hline Below ankle AMPU & $15(5.9)$ & 0.823 & & $0.139-1.000$ & $0.699-0.946$ \\
\hline Above ankle AMPU & $28(I I)$ & 0.717 & & $0.030-1.000$ & $0.608-0.826$ \\
\hline DFU & $98(69.5)$ & 0.681 & & $0.007-1.000$ & $0.623-0.738$ \\
\hline Clean wound & $24(9.4)$ & 0.817 & & $0.320-1.000$ & $0.739-0.891$ \\
\hline Non-ischemic, infected ulcer & $25(9.8)$ & 0.813 & & $0.221-1.000$ & $0.723-0.897$ \\
\hline Ischemic, non-infected ulcer & $25(9.8)$ & 0.534 & & $0.151-1.000$ & $0.428-0.644$ \\
\hline Ischemic, infected ulcer & $24(9.4)$ & 0.559 & & $0.007-1.000$ & $0.427-0.684$ \\
\hline COM & & 0.903 & & $0.043-1.000$ & $0.870-0.937$ \\
\hline DR & $27(10.6)$ & 0.924 & & $0.658-1.000$ & $0.884-0.963$ \\
\hline ESRD & $28(11)$ & 0.898 & 0.19 & $0.043-1.000$ & $0.823-0.973$ \\
\hline CAD & $27(10.6)$ & 0.889 & 0.15 & $0.439-1.000$ & $0.823-0.948$ \\
\hline CON & $31(12.2)$ & 0.961 & 0.06 & $0.767-1.000$ & 0.939-0.981 \\
\hline
\end{tabular}

Abbreviations: AMPU, amputation; CAD, coronary artery disease; COM, other diabetic complications; CON, control; DFU, diabetic foot ulcer; DF, diabetic foot; DR, diabetic retinopathy; ESRD, end stage renal disease.

Diabetes, Metabolic Syndrome and Obesity: Targets and Therapy is an international, peer-reviewed open-access journal committed to the rapid publication of the latest laboratory and clinical findings in the fields of diabetes, metabolic syndrome and obesity research Original research, review, case reports, hypothesis formation, expert opinion and commentaries are all considered for publication. The manuscript management system is completely online and includes a very quick and fair peer-review system, which is all easy to use. Visit http://www.dovepress.com/testimonials.php to read real quotes from published authors.

Submit your manuscript here: https://www.dovepress.com/diabetes-metabolic-syndrome-and-obesity-targets-and-therapy-journal 